\title{
O LUGAR DA MÃE NA PRÁTICA DA AMAMENTAÇÃO DE SUA FILHA NUTRIZ: o estar junto
}

\author{
Ana Rita Marinho Machado* \\ Ana Márcia Spanó Nakano** \\ Ana Maria de Almeida*** \\ Marli Villela Mamede ${ }^{\star \star \star *}$
}

\section{Resumo}

As inquietações dos autores giram em torno da estrutura de apoio à mulher frente ao aleitamento materno em seu meio relacional familiar. Trata-se de um estudo qualitativo que tem por objetivo compreender o significado da prática de amamentar entre mães e filhas nutrizes bem como, identificar como a mãe se percebe como suporte à sua filha nutriz e viceversa. Utilizou-se como referencial teórico, a construção histórica social da mulher para o exercício da maternidade. A amostra constituiuse de 10 mulheres, sendo 5 nutrizes (primíparas) e suas respectivas mães. A participação da mãe na maternidade da filha era de "estar junto", compartilhando seus conhecimentos e suas experiências vivenciadas.

Descritores: aleitamento materno; apoio social; maternidade

\begin{abstract}
The authors' disquietudes are related to the structure for supporting women to breastfeed within their family environment. It is a qualitative study aiming at understanding the significance of breastfeeding among mothers and primiparous daughters, as well as identifying how the mother perceive herself as a means of support for her primiparous daughter and vice versa. The historic social construction of women for maternity has been used as a theoretical referential. The sample was made up of 10 women-five primiparous daughters and their mothers. The participation of the mother in her daughter's maternity was "to be along with her", sharing knowledge and life
\end{abstract} experiences.

Descriptors: breastfeeding; social support; maternity

Title: The mother's role in breasfeeding her promiparous daughter: "the toget herness"

\section{Resumen}

Las inquietudes de los autores se relacionan con la estructura de apoyo a la mujer durante el periodo de lactación, dentro de las relaciones familiares. Se trata de un estudio cualitativo, que tiene por objetivo comprender el significado de la práctica de la amamantación entre madres e hijas nutrices, así como identificar si la madre se da cuenta que es un soporte para su hija nutriz y viceversa. Se utilizó como referencial teórico, la construcción histórica social de la mujer para el ejercicio de la maternidad. La muestra estaba constituida de 10 mujeres, 5 nutrices (primíparas) y sus respectivas madres. La participación de la madre en la maternidad de la hija es la de "estar a su lado", compartiendo sus conocimientos y las experiencias vividas.

Descriptores: lactación materna; apoyo social; maternidad

Titulo: El papel de madre en la práctica de la lactación de su hija nutriz: "estar a su lado"

\section{Introdução}

De acordo com a OMS/UNICEF, a amamentação não é totalmente instintiva no ser humano, muitas vezes tem que ser aprendida para ser prolongada com êxito, e a maioria das nutrizes precisa de reforço e apoio constantes.

Corroborando com tais idéias observamos que as mulheres ao se depararem pela primeira vez com o aleitamento materno, requerem que thes sejam apresentados modelos ou guias práticos de como devem se conduzir nesse processo. $\mathrm{Na}$ maioria das vezes, têm como primeira referência o meio relacional familiar, suas amizades e vizinhança nos quais estão inseridas. Há de considerar, ainda, que embora a amamentação tenha início em um contexto hospitalar sob a hegemonia do profissional de saúde, esta só se estabelece no ambiente doméstico sob o domínio das mulheres ${ }^{(1)}$.

Nesse sentido, é no ambiente doméstico e feminino que as mulheres tentam, em primeira mão, resolver os problemas relacionados ao aleitamento materno, revelando a presença de múltiplos poderes nesse processo(2).

O marido e a mãe da nutriz são importantes influenciadores no processo de aleitamento materno, pois o primeiro apresenta-se como agente estimulador da prática e a mãe como modelo de referência ${ }^{(3)}$. Já os profissionais de saúde surgem como incentivadores da prática, dando ênfase aos procedimentos técnicos, tais como cuidados com a mama, técnicas para amamentação, entre outros. Como parte desse jogo de relações que influencia o aleitamento materno, aparecem, ainda, colegas, vizinhas e a própria mídia.

Os profissionais de saúde, parentes, vizinhos ou amigos são os responsáveis pela introdução da mamadeira e do desmame ${ }^{(4)}$. No entanto, considera-se que o apoio do marido/ companheiro talvez seja a fonte mais significativa de estímulo à amamentação que uma mulher recebe ${ }^{(5)}$.

Outros autores realçam o papel das mulheres no meio familiar, como importante elemento de referência. A arte de amamentar não é inata à mulher, mas tem sido aprendida durante séculos, através do contato direto de mulheres experientes com as menos experientes ${ }^{(6)}$. Ainda sobre o assunto, podemos referir as mulheres do meio familiar: mães, avós, tias maternas e irmãs mais velhas, como exemplos a serem seguidos, fontes seguras de informação não só para a amamentação( ${ }^{(7)}$.

Nessa configuração de relações favoráveis ao aleitamento materno, destacamos o papel da avó materna do recém-nascido, a mãe da nova mãe; que exerce influência significativa sobre a jovem mãe, sua filha, refletindo-se na forma como essa percebe e age no desempenho das funções maternas. No processo de socialização familiar, as mulheres são treinadas para exercerem sua função primordial, a maternidade e, por extensão, a de educadora, de modo que preparam as filhas, futuras mães, para o cuidado materno. Assim, a menina se identifica com a própria mãe quando cresce, identificação que a produz mãe(8)

A mulher como ser social, no exercício dos atributos maternos, busca abastecer-se de informações no universo de significados interiorizados, durante sua vida. Por meio do processo contínuo de socialização mediado por esses significados, incorpora outros significados para compreender,

\footnotetext{
* Enfermeira. Mestre em Enfermagem. Professora do Departamento de Enfermagem da Faculdade de Medicina do Triângulo Mineiro - Uberaba. **Enfermeira. Professora Doutora do Departamento de Enfermagem Materno Infantil e Saúde Pública da Escola de Enfermagem Ribeirão Preto/USP. ***Enfermeira. Professora Doutora do Departamento de Enfermagem Materno Infantil e Saúde Pública da Escola de Enfermagem Ribeirão Preto/USP.

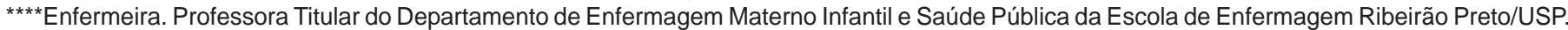
E-mail do autor: nakano@eerp.usp.br
} 
interpretar e atuar nas situações vivenciadas. Entretanto, descontinuidades socializatórias podem se apresentar, revelando conflitos entre o sistema simbólico interiorizado e a realidade contextual em que a mulher se insere ${ }^{(9)}$

$\mathrm{Na}$ transmissão de valores à nutriz, a mãe poderá transmitir, também, tabus, crenças e proibições inerentes a um dado contexto histórico-social, atuando ainda de forma indireta como elemento desestimulador ou estimulador à amamentação, quando sua experiência é tomada na família como padrão de amamentação.

Durante o parto, o obstetra assiste a quatro nascimentos: nasce uma criança, um pai, uma mãe e uma família(10). Às vezes, também nasce uma avó que pode ser muito útil ou nociva para esta mãe.

$\mathrm{Na}$ amplitude deste campo de investigação, é nosso intuito compreender, sob a ótica das nutrizes e de suas respectivas mães, a lógica que sustenta a prática do aleitamento materno e identificar o significado da participação das mães na maternidade das filhas.

Pressupomos que os significados atribuídos pelas mulheres acerca de suas vivências no aleitamento materno reproduzem, em parte, os significados construídos por suas mães, estando estes fundados em experiências maternas anteriores. Entretanto, conflitos e contradições podem estar presentes.

Acreditamos que a compreensão destas questões nos possibilitará não só direcionar nossas ações à mãe da nutriz, como também criar estratégias mais efetivas direcionadas à assistência oferecida à mulher/nutriz, com o fim de lhe oferecer subsídios para que tenha apoio e suporte social efetivos, de forma a proteger e promover sua prática de aleitamento materno.

\section{Procedimentos metodológicos}

Desenvolvemos uma pesquisa qualitativa no município de Uberaba, localizado na micro-região do Triângulo Mineiro, com mulheres primíparas, no período pós-parto entre 1 a 6 meses, que estavam amamentando. Um outro critério para sua inclusão na pesquisa é que suas mães deveriam estar envolvidas no processo, compartilhando das vivências de suas filhas, e que ambas, mãe e filha consentissem participar da mesma. Assim fizeram parte do recorte empírico desse estudo 10 mulheres, entre as quais: 5 nutrizes e respectivas mães. 0 primeiro contato foi na UBS quando da realização do teste do pezinho e/ou vacina BCG, entretanto; realizamos as entrevista no domicílio.

De acordo com as diretrizes de normas éticas em pesquisa com seres humanos os dados foram coletados por meio de entrevista semi-estruturada, direcionada por roteiros distintos para as nutrizes e suas mães, após o consentimento livre esclarecido e assinatura do termo pelas informantes.

Os dados foram submetidos à técnica de análise de conteúdo que permitiu articular as estruturas semânticas (significantes) com estruturas sociológicas (significados) dos enunciados dos depoimentos de mães e filhas. Optamos pela análise temática, pois ela permitiu identificar, nos depoimentos dos sujeitos o significado das vivências do processo de aleitamento e sua reprodução através de gerações ${ }^{(11)}$. Assim os relatos, tanto das mães como filhos foram lidos e relidos, procurando identificar unidades temáticas que nos auxiliassem na compreensão sobre como mães e filhas/nutrizes percebem e agem frente o aleitamento materno. Assim foi possível identificar as seguintes unidades temáticas: a lógica que sustenta a prática do aleitamento materno em ambas as gerações; o perfil das mulheres para amamentar na concepção das mães e das filhas e a participação das mães na maternidade das filhas.

\subsection{Os sujeitos investigados}

A idade das mães das nutrizes variou entre 44 e 49 anos, com a média de 47 anos, enquanto o grupo das filhas apresentou idade variável entre 17 e 29 anos, estando a média em 21,8 anos de idade.

Comparando a média da idade das mães das nutrizes por ocasião do nascimento do primeiro filho (25,2 anos) com a média da idade das filhas (21,8 anos), podemos observar que estas iniciaram a procriação em idade mais jovem que a das suas mães. Dados do Ministério da Saúde revelam que em 1993, de todos os partos realizados pelo SUS, $21,41 \%$ foram de jovens com 15 a 19 anos. Em 1996, esse percentual subiu para $24,63 \%^{(12)}$.

Quanto ao nível de escolaridade das mães das nutrizes, 03 possuíam o $1^{\circ}$ grau incompleto; 01 concluiu o $2^{\circ}$ grau e outra o $3^{\circ}$ grau. Em relação às filhas, 03 concluíram o $2^{\circ}$ grau; 01 possuía o $2^{\circ}$ grau incompleto e 01 estava cursando o $3^{\circ}$ grau.

Quanto à ocupação, 03 mães das nutrizes não trabalhavam fora do lar por ocasião da maternidade e 02 eram autônomas, porém, atualmente, todas as mulheres deste grupo têm uma ocupação fora do lar. No que diz respeito às filhas, 03 delas participavam do mercado de trabalho formal (estando, inclusive, usufruindo a licença gestante).

O crescimento da participação feminina no mercado de trabalho brasileiro foi uma das mais marcantes transformações sociais ocorridas no país desde os anos 70. As estatísticas têm revelado que a presença das mulheres no mercado de trabalho brasileiro é cada vez mais intensa e diversificada e não mostra nenhuma tendência de retrocesso(13). Portanto, as mulheres vêm beneficiando-se da democratização da educação formal no Brasil, nas últimas décadas ${ }^{(14)}$. As mulheres participam do sistema educacional brasileiro na mesma proporção que os homens.

Sobre a prática do aleitamento materno dos sujeitos da investigação, entre as mães das nutrizes apenas 02 apresentam duração média de aleitamento materno além dos 06 meses. Aspectos sociais e culturais são apresentados como delimitadores do tempo de amamentação. Entretanto, observase que todas as nutrizes (filhas) apresentaram uma duração de aleitamento materno até os 6 meses.

À medida que as dificuldades frente à continuidade da amamentação se mostram presentes, as mulheres deixam de se ater ao idealizado para adaptar-se à sua condição específica, o que justifica o fato de apresentarem um discurso diferente da sua prática, onde predomina o desmame precoce. Pesquisa Nacional, realizada recentemente, revela que as mães brasileiras, em média, amamentam exclusivamente por 34 dias.

\section{A lógica que sustenta a prática do aleitamento materno em ambas as gerações}

\subsection{Aleitamento materno com finalidade nos benefícios para a criança}

Os aspectos relacionados ao benefício que o aleitamento materno traz à criança mostram-se consolidados para ambas as gerações. O conhecimento expresso pelas mulheres sobre o aleitamento materno lembram as mensagens difundidas pela mídia, enfatizando as propriedades do leite humano e sua influência na condição de saúde da criança.

Eu acho importante, eu acho que toda mãe, assim, tem que amamentar, porque é bom para a mãe e melhor ainda para o bebê Diana (Filha).

\subsection{Aleitamento materno como prática aprendida}

O aprendizado para as mães das nutrizes acerca da prática do aleitamento materno é entendido como algo intimamente ligado à transmissão de experiência já vivida e seguida enquanto fonte de autoridade para conduzir-se na prática da amamentação.

O que eu aprendi com a minha mãe, porque a gente não tinha orientação, né? Da forma que ela sabia também ela me passou Anábile (Mãe).

Já as filhas buscam referenciar o seu fazer como nutriz 
nas orientações técnicas e científicas dos profissionais de saúde. Hoje a gente tem aonde correr, aonde apoiar, né? Porque você pode ir numa médica, você tem as enfermeiras que sempre tão lá, né? Tão disponível para você perguntar, para você questionar. Valquíria (Filha).

Verificamos um certo distanciamento na rede de aconselhamento e de experiência familiar quando as filhas as substituem por recomendações dos profissionais de saúde. É reconhecido o valor do conhecimento técnico-científico também pelas mães das nutrizes, como sendo o mais apropriado. Com isso, as mães perdem o lugar de destaque como autoridade potencial na transmissão de normas e costumes.

É , eu acho que está melhor. As coisas estão mais fáceis, da pessoa, assim, saber melhor. Tem mais orientação, do que a gente recebia. Maria do Socorro (Mãe).

Tem-se a considerar alguns aspectos sugestivos de influências no desencadeamento desse movimento de descontinuidade evidenciado na fala dessas mulheres. Com a medicalização, as mulheres foram alijadas, paulatinamente, de seus conhecimentos, que foram aos poucos substituídos pelo discurso competente, ou seja, aquele que é instituído como verdadeiro. As mulheres foram esvaziadas de si mesmas, ao mesmo tempo em que passaram a responder à determinação externa, isto é, à dominação(15).

Destituída do saber acumulado e transmitido pelas gerações e desvalorizada por suas experiências de vida, as mulheres mostram-se dependentes de padrões normatizadores sobre a prática da amamentação. Neste contexto, o profissional de saúde ganha destaque, sendo valorizado e até mesmo tomado pelas mulheres como referência para amamentação, já que para elas não há uma sustentação junto ao modelo tradicional.

\subsection{Amamentar é da natureza da mulher}

As mulheres, identificadas à natureza devido às suas especificidades fisiológicas, foram tomadas como bases fundamentais de construção da figura da "mãe higiênica" criada no passado. A mulher que não amamentava dizia-se que rompia duplamente os cânones naturais. Em primeiro lugar porque conduzia de modo contrário a todas as fêmeas da classe dos mamíferos; em segundo lugar, porque contrariava sua outra vocação 'natural', a de ser mãe, conforme figurino higiênico(16).

É normal, via assim, a mamãe amamentar, todas as mães amamentar, então parece que, né? a gente [...] quando nascia já ia amamentar sem alguém orientar, Maria do Socorro (Mãe).

Entretanto, a amamentação considerada como instintiva, natural e biológica para os mamíferos, tem se apresentado na prática como facultativa para a espécie humana. O que revela ser a amamentação uma prática determinada não só pela biologia, mas também condicionada pela sociedade e pela cultura, sendo portanto definida como híbrido natureza-cultura ${ }^{(17)}$

A construção social das mulheres para a maternidade, tida como fazendo parte da própria natureza, tem manifestado nelas um certo juízo moral quando se vêem diante da possibilidade de utilizar-se de meio alternativo para substituirse ou inclusive aliviar-se na função de nutriz, como podemos observar nas falas tanto das mães quanto das filhas nutrizes.

Parece que as mães antigamente eram mais, sei lá, mais conscientizadas, não sei. E não tinha esse negócio assim, desse leite 'NAN', leite ninho, era só peito, peito. Elenice (mãe)

Percebem-se desviantes da natureza quando imprimem um julgamento moral frente à adoção de meios alternativos para aliviar-se ou substituir-se nessa função.

\subsection{O perfil das mulheres para amamentar na concepção das mães e das filhas}

\subsubsection{Ser nutriz é ser paciente e ter vontade}

As imposições morais e de comportamento sobre o corpo feminino fundamentam-se na reprodução como função precípua da mulher. Nesse sentido, o corpo socialmente adaptado ao modelo de maternidade de doação e sacrifício tem força para legitimar a prática efetiva da amamentação por um tempo duradouro e recomendado. Isso foi observado nas duas gerações.

O centro agora é o neném, é o filho. Agora...é tudo mesmo. Tudo que eu faço, eu faço pensando nele. Diana (filha).

Você teve seu bebezinho, minha filha, você vive por ele assim, enquanto ele for bebê, sabe? Ângela Maria (Mãe).

Para ambas as gerações, as mulheres do passado eram mais dotadas de paciência, vontade e perseverança, aspectos que as atuais mães são destituídas, o que justifica para elas o fato das mulheres amamentarem mais no passado que na atualidade.

Amamentam, mas acho que não é assim, igual era, não. Tem muitas mães que não gosta muito não. Não tem paciência, Elenice (mãe).

Amamentar significa conhecimento, tempo, disponibilidade, boa alimentação, tranqüilidade e outros requisitos, que via de regra, não estão disponíveis para a maioria das mulheres ${ }^{(18)}$.

Observamos que as mulheres buscam aterem-se a um limite temporal de dedicação integral às funções maternas/ amamentação, de forma não declarada mas sob manifestação invisível e por vezes, até inconsciente que limitam a amamentação com base na sua incapacidade fisiológica para tal função(19). Tal justificativa as protegem de qualquer desaprovação do social, obtendo a solidariedade do grupo a qual pertencem.

\subsubsection{Ser nutriz é privilegiar a amamentação em detrimento à imagem corporal}

A questão da estética tem sido uma das preocupações das mulheres na atualidade, o que, na opinião de mães e filhas, estaria determinado o abandono da amamentação por medo do "peito cair" e da flacidez.

É... como que eu posso falar? Assim, padrão físico, muito preocupada assim, em manter o corpo e tal. Acha que amamentar vai atrapalhar. Lígia (filha)

Algumas mulheres apontam aspectos estéticos como fundamentais na escolha ou não da amamentação, mas estes não parecem ser um fator determinante na decisão de amamentar ou não(18). O sentido que os sujeitos atribuem às mamas integra a rede de sentidos do grupo social do qual faz parte. Neste aspecto a mama, apresenta-se ora significativamente ligada à maternidade, ora à sexualidade na dependência de valores sociais e até mesmo do momento circunstancial e singular de vida de cada mulher.

\subsection{A participação das mães na maternidade das filhas}

\subsubsection{Estreitamento dos vínculos}

Os laços mãe-filha estreitam-se por ocasião da maternidade da filha, por trazerem de forma concreta, a representação simbólica do que seja ser mãe.

A gente aprende a dar mais valor na mãe. Aí a gente aprende o tanto que uma mãe gosta de um filho e sabe que tudo que faz é para o bem do filho, nada é por acaso. Diana (filha)

Na vivência da maternidade, as filhas passam a dar valor às suas mães, renovando o "vínculo fusional" que tinham com elas. A maternidade que poderia servir como linha de delimitação entre infância e idade adulta da mulher, não traz em si, como experiência o movimento de separação de um vínculo visceral, mas ao contrário, re-encena, fora do ventre a visceralidade deste vínculo(20).

$\mathrm{Na}$ visão das mães das nutrizes, tal condição manifestase na mudança do comportamento de suas filhas para com elas, tornando-as mais afetivas. Há muitas vezes uma reconciliação entre mãe e filha que anteriormente envolveram- 
se em algum atrito.

[...] mas depois desse bebê, ela tem sido um pouquinho mais carinhosa comigo, sabe? Mesmo quando ela fica nervosinha assim comigo, ela já fala com mais carinho, sabe? [...] Eu tenho impressão que a filha se sente um pouco [...] o sentimento da mãe, né? Ângela Maria (mãe).

O sentido feminino de relação e vínculo propicia espaço para transmissão de valores e conhecimentos das mães para as filhas respaldados na experiência e na tradição do que é ser mãe. A mãe transmite às filhas as mensagens que recebeu muitas vezes de sua mãe.

A minha mãe foi muito importante. Eu espelhei muito nela, quando elas nasceram [...] o que eu sei assim, eu não sei muito, mas o pouco que eu sei eu passo para a ela, Glória (mãe).

Desta forma, as mães atuam junto às filhas, dão força, incentivo e às vezes, usam de seu status de mãe para lembrarIhes os deveres e responsabilidades de ser mãe(21).

[...] que às vezes chora lá dentro, ela sai lá fora: 'Lígia, põe uma fraldinha na cabeça dele', 'Ah, mãe. Ta calor'. Eu falei assim: 'Mas dá dor de barriga'. Ué mãe! Você ta pensando que é mãe dele? Eu falei: 'eu não sou mãe dele não, mas sou vó. Faz favor, Amábile (mãe).

Percebemos que o social constrói a identidade de gênero para o exercício dos papéis maternos, e, na maioria das vezes, é a própria mulher que se constitui elemento de reprodução e manutenção dessa identidade. São situações que podem gerar relação conflitante entre mãe e filha quanto ao que significa ser mãe.

\subsubsection{Ajudando nos afazeres domésticos e prestando cuidados}

O suporte e ou apoio do seu meio relacional, na maioria das vezes, advém da própria mãe durante as primeiras semanas no pós-parto.

A minha mãe sempre me ajudou muito nesse ponto, sabe? Ela faz quase todo o serviço. Agora que eu estou começando a fazer o serviço de casa. Naira (filha).

Arranjos familiares são realizados para que a mãe possa ajudar na maternidade da filha: mudando de residência temporariamente, conciliando licença no trabalho com o período de pós-parto da filha.

Algumas mães revivem com a maternidade das filhas as próprias dificuldades quando se tornaram mães. O vínculo de proteção para com a filha que está em fase de restabelecimento puerperal é re-encenado.

Ah, no resguardo [...] ela ficava muito brava comigo. Ela falava: mãe! Eu não estou doente! [...]Eu tive que ter um pouco mais de repouso, por causa da operação né? Eu queria fazer tudinho para ela, né? Só que ela não aceitava não, Ângela Maria (mãe).

O reconhecimento do valor social da prática do cuidado prestado pelas mulheres é um fato social atribuído à mulher devido à antiqüíssima divisão social do trabalho ${ }^{(22)}$. A mãe ao prestar cuidado se respalda no conhecimento interiorizado do vivido, na experiência de toda uma vida. A mãe como prestadora de cuidados toma para si a responsabilidade e o compromisso ${ }^{(23)}$

O cuidar é uma atividade regida pelo gênero (...) conforme os papéis tradicionais de gênero em nossa sociedade implica que os homens tenham 'cuidado com' (preocupar-se) e as mulheres 'cuidam de', que se reflete sobre as obrigações sociais atribuídas a quem cuida e sobre quem faz essa atribuição. Nesse sentido, as mães expressam no ato de cuidar a essência do feminino de ser para os outros ${ }^{(23)}$.

\subsubsection{Estar junto}

$\mathrm{Na}$ situação particular da participação da mãe na maternidade da filha, o "estar junto" é compartilhar dos conhecimentos e experiências. Embora possam ocorrer conflitos, simultaneamente abre-se espaço para elas perceberem o quanto ambas têm em comum.

Ela sempre estava junto de mim. A participação dela é estar junto, né? Vanda (Filha).

Continuar, junto, o tempo todo [...] Por que mãe é mãe. Maria Socorro (Mãe).

Ambas têm em comum a marca da construção social pautada nas diferenças entre os gêneros, que afetaram ou afetam suas vidas e limitam suas escolhas. Nesse sentido, a mãe tende assumir as funções maternas e domésticas da filha e cria oportunidade para que ela conquiste seu espaço em outras esferas.Tal situação é sugestiva de que, inconscientemente, a mãe esteja preocupada para que a filha não repita as suas experiências de vida. Mas guarda em si mesma a essência do feminino de sacrificar-se pelo outro (filha), sendo esta situação percebida pela filha de forma mais concreta,como podemos observar nas falas.

eu ainda tenho muita vida pela frente, muita coisa para fazer ,então eu vou precisar muito da ajuda dela. Quero continuar estudando,né? terminar o terceiro, fazer mais alguma coisa [...] ela vai precisar me ajudar mesmo, Naira (Filha).

No entanto, não deixa de dar suporte à filha caso esta tenha escolhido galgar outros espaços para além do doméstico.

Quantas das vezes eu saí daqui e levei a menina lá no colégio, sabe? para ela dar de mamar para a menina. [...] Às vezes estava chovendo, aquele sol quente, eu saía daqui, né? Glória (Mãe).

Portanto, a consciência feminista sobre novas possibilidades, novos espaços para as mulheres está levando a uma reavaliação da importância do relacionamento recíproco entre as mulheres e uma nova conscientização de que tal relacionamento encerra um enorme potencial de apoio mútuo.

Nesse sentido, a mãe compartilha os momentos de maturidade da filha, constitui elemento de aprendizado, ajuda, fortalece e reafirma as especificidades do gênero feminino. Dessa forma, possibilita que a filha esteja presente nas diferentes esferas sociais e ocupe outros espaços além do doméstico.

\section{Considerações finais}

O universo simbólico feminino de ambas as gerações, contém formulações que reiteram a amamentação como finalidade precípua aos benefícios para a criança. Na prática de aleitamento materno, as mulheres valorizam o aprendizado como base para que a amamentação seja efetiva. A influência potencial de transmissões de regras e autoridade, tradicionalmente estabelecidas pela figura materna, perde seu lugar de destaque ante as dificuldades específicas das filhas e um novo arranjo se estabelece: permanece o vínculo mãe-filha, mantém-se a hierarquia e a autoridade legítima como procedimento lógico. Entretanto, inverte-se a posição dos agentes, a mãe submete-se ao conjunto de valores defendidos pela filha que estão fundamentados no saber científico de poder dos profissionais de saúde.

$\mathrm{Na}$ concepção de mães e filhas, a "vontade" e a "paciência" para amamentar é fator fundamental e constituinte da feminilidade e identidade de mulher. As mulheres do passado são apresentadas como mais dotadas da "natureza maternal" do que as da atualidade, o para elas justifica o fato de, no passado, amamentar-se mais.

Na forma de se organizar para o desempenho das tarefas maternas e domésticas, a parentela consangüínea parece ocupar um lugar significativo nas redes de ajuda mútua, tanto no presente como no passado. Neste sentido, a participação da mãe na maternidade da filha emerge significados simbólicos do que seja ser mãe, renovando os vínculos , consolidando-os até mesmo reconciliando-os. A concretude desta participação para as mães está na organização e desenvolvimento das tarefas domésticas e no prestar o cuidado à filha. 
Percebemos uma descontinuidade na forma de participação das mães na maternidade das filhas, que no passado era uma relação essencialmente hierárquica. Hoje, ao contrário, as influências são recíprocas e cada vez mais semelhantes, o que foi simbolicamente apresentado pelos sujeitos da pesquisa como "estar junto", que em sua singularidade envolve compartilhar dos conhecimentos e experiências.

\section{Referências}

1. Nakano AMS, Shimo AKK. Experiência de um grupo de mulheres frente à primeira mamada do filho. In: Anais do $9^{\circ}$ Encontro Paulista de Aleitamento Materno;1998 ago 24-28;São Paulo, Brasil. São Paulo: Unifesp;1998.p.102-3.

2. Nakano AMS. O aleitamento materno no cotidiano feminino [tese de doutorado em enfermagem]. Ribeirão Preto (SP): Escola de Enfermagem, Universidade de São Paulo;1996.170f.

3. Machado ARM, Nakano MAS, Shimo AKK. A influência de terceiros na prática do aleitamento materno. São Paulo: Universidade Federal de São Paulo;1998.p.60-2.

4. Rea MF, Cukier R. Razões de desmame e de introdução da mamadeira: Uma abordagem alternativa para o seu estudo. Rev Saúde Pública, São Paulo 1998;22(3):184-91.

5. Giugliani ERJ. Amamentação: Como e por que promover. J Pediatria 1994; 70(3):138-51.

6. Bittar ER. Questões de incentivo ao aleitamento materno no pré natal. Rev Ginecol Obstet, São Paulo 1992;3(2):91-4.

7. Almeida MIM. Maternidade: um destino inevitável? Rio de Janeiro: Campus;1987.131p.

8. Chodorow N. Psicanálise da maternidade: Uma crítica a Freud a partir da mulher. Rio de Janeiro: Rosa dos Tempos;1990.319p.

9. Bergher PL, Luckmann T. A construção social da realidade: Tratado de sociologia do conhecimento. $11^{\mathrm{a}}$ ed. Petrópolis(RJ): Vozes; 1994. $247 f$.

10. Noronha DL, Lopes G, Montgomery M. Tocoginecologia psicossomática. São Paulo: Editora Almed;1993.235p.

11. Bardin L. Análise de conteúdo. $7^{a}$ ed. Lisboa: Edições 70;1977.225p.

12. Ministério da Saúde (BR). Saúde do Adolescente. Brasília (DF) [online]. Disponível em: <http://www.saude.gov.br/>. Acessado em: 24 out 2000.
13. Bruschin IC. Trabalho da mulher no Brasil: Tendências recentes. In: Saffiotti HIB, Vargas Muñoz-Vargas M, organizadores. Mulher Brasileira é assim. Rio de Janeiro: Rosa dos Tempos;1994.228p.

14. Rosemberg F. A educação de mulheres jovens e adultas no Brasil. In: Saffiotti HIB, Vargas Muñoz-Vargas M, organizadores. Mulher Brasileira é assim. Rio de Janeiro: Rosa dos Tempos;1994.288p.p.2762.

15. Rocha Coutinho ML. Tecendo por trás dos panos: a mulher nas relações familiares. Rio de Janeiro: Rocco;1994.249p.

16. Costa JF. Ordem médica e norma familiar. Rio de Janeiro: Graal; 1983.282p.

17. Almeida JAG, Gomes R. Amamentação: Um híbrido natureza-cultura. Rev Lat Am Enfermagem, Ribeirão Preto (SP): 1998 jul;6(3):71-76.

18. Bemudez XPCD. Da natureza, da cultura e da amamentação: Um estudo do centro de lactação de Santos [dissertação de mestrado]. Brasília (DF): Instituto de Ciências Humanas, Universidade de Brasília;1997.187f.

19. Nakano MAS, Mamede MV. A prática do aleitamento materno em um grupo de mulheres brasileiras: movimento de acomodação e resistência. Rev Lat Am Enfermagem, Ribeirão Preto (SP) 1999 jul;7(3):69-76

20. Oliveira RD. Elogio da diferença: O feminino emergente. $3^{\mathrm{a}}$ ed. São Paulo: Editora Brasiliense;1993.150p.

21. Primo CC, Caetano LC. A decisão de amamentar da nutriz: Percepção de sua mãe. J Pediatria, 1999; 75(6):449-55.

22. Colliere MF. Promover a vida: da prática das mulheres de virtude aos cuidados de enfermagem. Lisboa: Sindicato dos Enfermeiros Portugueses; $1989.385 \mathrm{p}$.

23. Tronto JC. Mulheres e cuidados: o que as feministas podem aprender sobre a moralidade a partir disso? In: Jaggar AM, Bordo SR. Gênero, corpo, conhecimento. Rio de Janeiro: Rosa dos Tempos;1997.348p. p.186-203.

24. Bardwick JM. Mulher, sociedade transição. São Paulo: Difusão Cultural;1979.225p.p.72-96.

Data de Recebimento: 27/07/2003

Data de Aprovação: 28/06/2004 